\title{
The effect of curing conditions on the expansion efficiency of MgO expansion agent
}

\author{
Yu Fang, Li Yongchao* \\ CCCC Forth Harbor Engineering Institute Co., Ltd., 510230 Guangzhou, China.
}

\begin{abstract}
In order to further promote the research and application of $\mathrm{MgO}$ expansion agent in concrete field, this paper carried out the effect of different humidity and temperature conditions on the expansion properties of mortar and mortar specimens mixed with $\mathrm{MgO}$ expansion agent. In addition, the mechanism of the factors affecting the sensitivity of the $\mathrm{MgO}$ expansion agent is revealed by combining microscopic technology. The results show that the higher the curing temperature and the greater the curing humidity, the greater the expansion efficiency of the $\mathrm{MgO}$ expansion agent. The temperature of $20 \sim 40^{\circ} \mathrm{C}$ has no obvious effect on the efficiency of the $\mathrm{MgO}$ expansion agent, but the expansion value of the specimen doubles as the temperature rises to $40 \sim 80^{\circ} \mathrm{C}$. Besides, the higher the curing humidity, the better the expansion efficiency of the $\mathrm{MgO}$ expansion agent, but the $\mathrm{MgO}$ expansion agent is more sensitive to the low humidity environment, and the specimen shrinks in the lower humidity environment $(\mathrm{RH}=60 \%)$.
\end{abstract}

\section{Introduction}

Due to the hydration reaction of the cementitious material, temperature changes and drying, the volume of concrete will shrink during hardening and use which will cause shrinkage stress inside the concrete. Once the shrinkage stress exceeds the tensile strength, the concrete structure will crack. The use of shrinkage-compensating concrete is an effective measure to solve the shrinkage cracks of engineering concrete [1, 2]. Traditional shrinkage compensation concrete mainly uses UEA expansion agent or UEA-CaO composite expansion agent. Traditional shrinkage compensation concrete mainly uses UEA expansion agent or UEA-CaO composite expansion agent. However, when these two expansion agents are mixed into cementitious materials, they often fail to compensate for the shrinkage of concrete due to improper curing, difficult to control the reaction, and no ability to compensate for shrinkage in the later stage, and even cause more serious cracks in the concrete. As a new type of expansion agent, $\mathrm{MgO}$ expansion agent has the characteristics of less water required for hydration reaction, controllable expansion reaction, stable hydration products, and compensation for the contraction of concrete in the middle and late stages. Due to the above advantages, $\mathrm{MgO}$ expansion agent has gradually received attention in the field of concrete engineering in recent years.

At present, $\mathrm{MgO}$ expansion agent has begun to be applied in industrial and civil construction, water transportation engineering and other fields [3, 4]. However, there is a huge difference in the shrinkage compensation effect of $\mathrm{MgO}$ expansion agent in engineering. The main factors affecting the shrinkage compensation performance of $\mathrm{MgO}$ expansion agent are the type and amount of expansion agent, curing temperature and humidity, etc. $[5,6]$. According to the existing research results, there are not many studies on the effect of curing temperature and humidity on the volume deformation of cement-based materials mixed with $\mathrm{MgO}$ expansion agents [7]. The mechanism of the factors affecting the sensitivity of $\mathrm{MgO}$ expansion agent is still unclear, and further research is needed.

In this paper, the free expansion value and limit expansion value of cement-based materials mixed with a moderately active $\mathrm{MgO}$ expansion agent under different temperature and humidity conditions are measured to study its expansion efficiency. The influence mechanism of temperature and humidity on the expansion characteristics of $\mathrm{MgO}$ expansion agent is preliminarily analysed, which can provide some references for the engineering application of $\mathrm{MgO}$ expansion agent.

\section{Materials and Methods}

\subsection{Raw materials}

The reference cement (P.I 42.5) is provided by the China Building Materials Science Research Institute. The physical performance of reference cement is shown in Table1. MgO expansion agent ( $\mathrm{M}$ type) is produced by Wuhan Sanyuan Special Building Materials Co., Ltd. The physical performance of $\mathrm{MgO}$ expansion agent (M type) is shown in Table 2. The fine aggregate adopts Xiamen ISO standard sand. Tap-water is used for mixing.

\footnotetext{
* Corresponding author: lyongchao1@eccc4.com
} 
Table 1. Properties of $\mathrm{MgO}$ expansion agent.

\begin{tabular}{cc}
\hline Index & Value \\
\hline Density & $3.16 \mathrm{~g} / \mathrm{cm}^{3}$ \\
Fineness & $1.1 \%$ \\
specific surface area & $342 \mathrm{~m}^{2} / \mathrm{kg}$ \\
Initial setting time & $157 \mathrm{~min}$ \\
Final setting time & $227 \mathrm{~min}$ \\
the 3d flexural strength & $5.7 \mathrm{MPa}$ \\
the 3d compressive strength & $27.2 \mathrm{MPa}$ \\
\hline
\end{tabular}

Table 2. Properties of $\mathrm{MgO}$ expansion agent.

\begin{tabular}{cc}
\hline Index & Value \\
\hline Water content & $0.07 \%$ \\
MgO content & $86.54 \%$ \\
Reaction time & $112 \mathrm{~s}$ \\
Initial setting time & $160 \mathrm{~min}$ \\
Final setting time & $200 \mathrm{~min}$ \\
\hline
\end{tabular}

\subsection{Methods}

Refer to the Test Method for Expansion Value of Expansive Cement (JC/T 313-2009) to test the free expansion value of the cement paste mixed with $\mathrm{MgO}$ expansion agent. Refer to the Concrete Expansion Agent (GB 23439-2017) to test the limit expansion value of mortar mixed with $\mathrm{MgO}$ expansion agent. The cement paste mixture is: cement $(1080 \pm 2.0 \mathrm{~g}), \mathrm{MgO}$ expanding agent $(120 \pm 0.5 \mathrm{~g})$ : water $(341.3 \pm 1.0 \mathrm{~g})$. The mortar mixture is: cement $(607.5 \pm 2.0 \mathrm{~g}), \mathrm{MgO}$ expanding agent $(67.5 \pm 0.5 \mathrm{~g})$ : sand $(1350 \pm 5.0 \mathrm{~g})$ : water $(270 \pm 1.0 \mathrm{~g})$.

In order to study the effect of curing temperature on the expansion performance of the mortar and mortar mixed with $\mathrm{MgO}$ expansion agent, the specimens were placed in water at $20^{\circ} \mathrm{C}, 40^{\circ} \mathrm{C}, 60^{\circ} \mathrm{C}$ and $80^{\circ} \mathrm{C}$ respectively. The temperature was controlled by the chamber with control precision within $\pm 1^{\circ} \mathrm{C}$. Regarding the influence of the humidity environment, the specimens were placed under the conditions of $\mathrm{RH}=100 \%, \mathrm{RH}=95 \%, \mathrm{RH}=60 \%$, and $\mathrm{RH}=0 \%$ at $20^{\circ} \mathrm{C}$ respectively.

\section{Results \& Discussion}

\subsection{The effect of environmental humidity}

Fig. 1(a) shows the test results of the free expansion value of the cement paste mixed with $10 \%$ magnesia expansion agent during the 90 days at $20^{\circ} \mathrm{C}$ and different environmental humidity. In 90 days, the free expansion value of the cement paste under the condition of $\mathrm{RH}=95 \%$ is basically equivalent to the expansion value of the specimen under $\mathrm{RH}=100 \%$ conditions. The free expansion value reached $3420 \mu \varepsilon$ and $3770 \mu \varepsilon$ respectively at 90 days, and there is a tendency to continue to expand after 90 days. The cement paste under $\mathrm{RH}=0 \%$ conditions have been in a slow expansion state, and the free expansion of the cement paste reaches $760 \mu \varepsilon$ at the age of 90 days. However, the specimen kept shrinking under the condition of $\mathrm{RH}=60 \%$. The shrinkage values of 3 days and 7 days reached $160 \mu \varepsilon$ and $320 \mu \varepsilon$ respectively. After 60 days, the shrinkage value was basically stabilized.
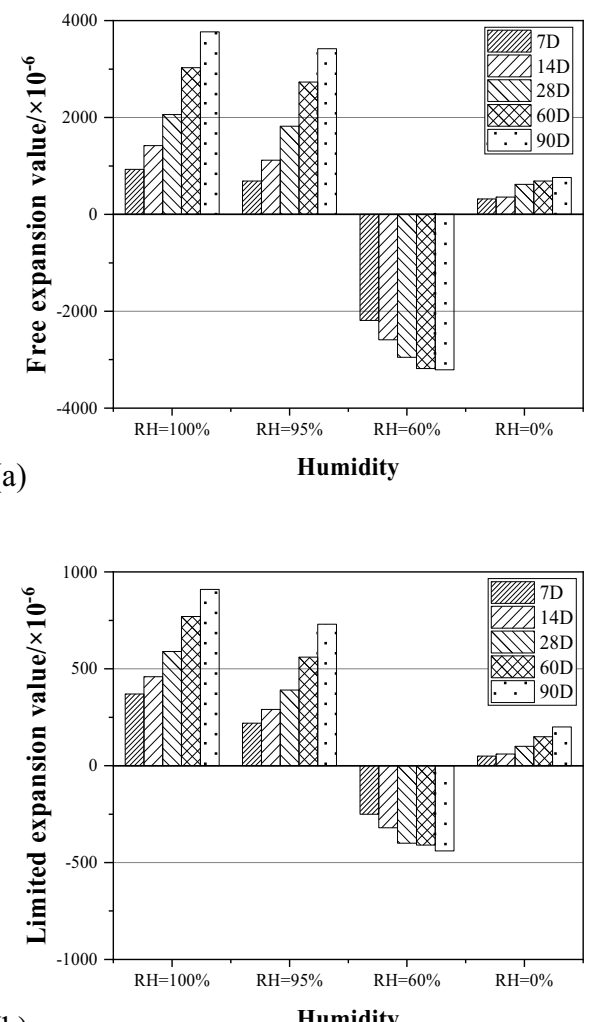

(b)

Humidity

Fig. 1. The effect of humidity on the properties of $\mathrm{MgO}$ expansion agent: (a) cement paster and (b) mortar.

Fig. 1(b) shows the test results of the limited expansion value of the cement paste mixed with $10 \%$ magnesia expansion agent during the 90 days at $20^{\circ} \mathrm{C}$ and different environmental humidity. The mortar specimens have been expanding within 90 days under $\mathrm{RH}=100 \%, \mathrm{RH}=95 \%$ and $\mathrm{RH}=0 \%$ curing conditions, while the mortar specimens have been shrinking under $\mathrm{RH}=60 \%$ conditions. Among them, the limiting expansion value of the mortar specimens under the curing condition of $\mathrm{RH}=100 \%$ within 90 days was greater than the specimen under the curing condition of $\mathrm{RH}=95 \%$. The specimens within 90 days slowly and continuously expanded throughout the test age under the curing condition of $\mathrm{RH}=100 \%$. The mortar specimen has been in shrinkage state under the condition of $\mathrm{RH}=60 \%$ within 90 days, and the shrinkage value is $440 \mu \varepsilon$ at $90 \mathrm{~d}$.

As the mention above, the higher the curing humidity, the more it can promote the performance of the $\mathrm{MgO}$ expansion agent. In addition, $\mathrm{MgO}$ expansion agent is more sensitive to low humidity environment, and it shows shrinkage in lower humidity environment, and produces larger shrinkage in the early age.

\subsection{The effect of curing temperature}

Fig. 2(a) shows the test results of the free expansion value of the cement paste mixed with $10 \% \mathrm{MgO}$ expansion agent under different curing temperatures in water during the 90 days. It can be seen from Fig. 2(a) 
that as the curing temperature increases, the expansion value of the cement paste mixed with $\mathrm{MgO}$ expansion agent gradually increases. In the first 7 days, the free expansion value of cement paste under water curing conditions at $20^{\circ} \mathrm{C}$ and $40^{\circ} \mathrm{C}$ is less than $2000 \mu \varepsilon$. But the expansion value of cement paste mixed with $\mathrm{MgO}$ expansion agent is $5970 \mu \varepsilon$ on the first 7 days at $60^{\circ} \mathrm{C}$.
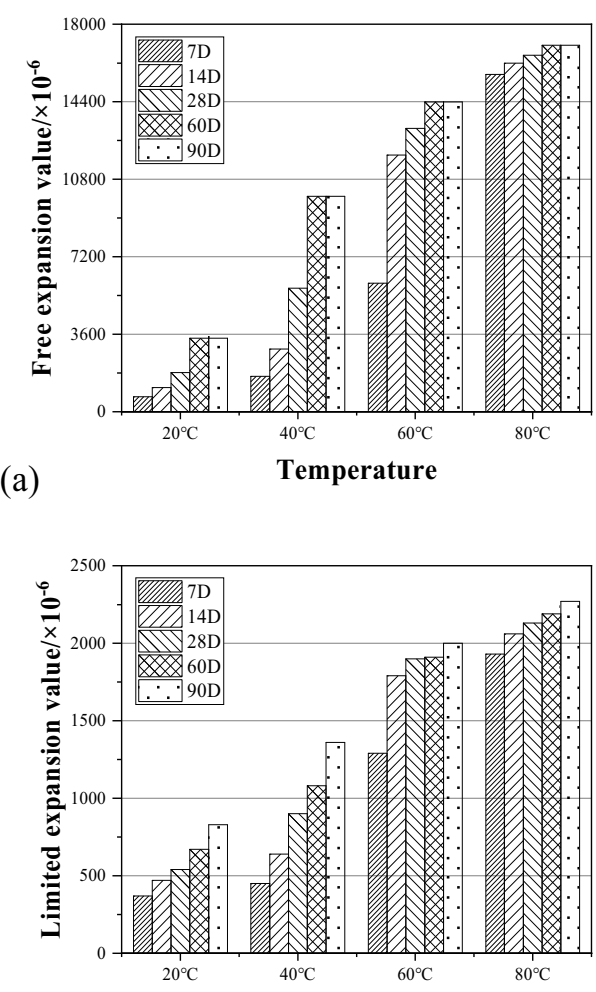

(b)

Fig. 2. The effect of temperature on properties of $\mathrm{MgO}$ expansion agent: (a) cement paster and (b) mortar.

Fig. 2(b) shows the test results of the limited expansion value of mortar specimens mixed with $10 \%$ $\mathrm{MgO}$ expansion agent at different curing temperatures in water during the 90 days. In the first 7 days, the limiting expansion values of the mortar specimens are basically the same under water curing conditions of $20^{\circ} \mathrm{C}$ and $40^{\circ} \mathrm{C}$, indicating that the temperature has little effect on the expansion reaction of the $\mathrm{MgO}$ expansion agent in the range of $20-40^{\circ} \mathrm{C}$. However, under the conditions of $40^{\circ} \mathrm{C}, 60^{\circ} \mathrm{C}$, and $80^{\circ} \mathrm{C}$, with the increase of curing temperature, the limiting expansion value of mortar specimens increased exponentially, indicating that in the range of $40 \sim 80^{\circ} \mathrm{C}$, the temperature has a significant effect on the $\mathrm{MgO}$ expansion agent.

As the mention above, the higher the curing temperature, the faster the hydration rate of the $\mathrm{MgO}$ expansion agent, and the greater the expansion rate and expansion value. This indicates that the $\mathrm{MgO}$ expansion agent is more sensitive to the temperature range of $40 \sim 80^{\circ} \mathrm{C}$, but not sensitive to the temperature range of $20 \sim 40{ }^{\circ} \mathrm{C}$.

\subsection{Temperature sensitivity analysis of $\mathrm{MgO}$ expansion agent}

In order to quantitatively evaluate the promoting effect of temperature gradient on the hydration reaction of $\mathrm{MgO}$ expansion agent, a Simultaneous Thermal Analysis (DSC) and Scanning Electron Microscope Analysis (SEM) test are carried out on the cement paste mixed with $\mathrm{MgO}$ expansion agent under different curing temperatures in water. The results are shown in Fig. 3 and Fig. 4.

It can be seen from the Fig. 3 that the temperature gradient does not uniformly increase the hydration reaction of $\mathrm{MgO}$ expansion agent. Within the range of $20-40^{\circ} \mathrm{C}$, the amount of $\mathrm{Mg}(\mathrm{OH})_{2}$ produced is not much different, only increasing by $7.43 \%$. However, the amount of $\mathrm{Mg}(\mathrm{OH})_{2}$ produced increased significantly at $40-60^{\circ} \mathrm{C}$, increasing by $26.12 \%$. The amount of $\mathrm{Mg}(\mathrm{OH})_{2}$ produced tends to be stable at $60-80^{\circ} \mathrm{C}$, only increases by $3.54 \%$ compared to $60^{\circ} \mathrm{C}$. This shows that the amount of $\mathrm{MgO}$ particles hydrated into $\mathrm{Mg}(\mathrm{OH})_{2}$ is not high when the temperature is lower than $40^{\circ} \mathrm{C}$.

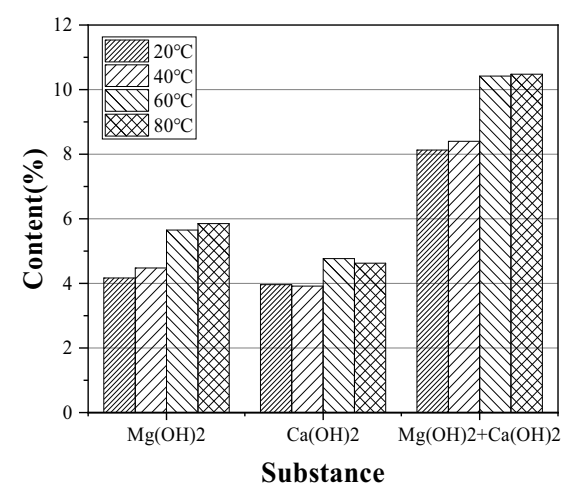

Fig. 3. Quantitative analysis of curing for $7 \mathrm{~d}$ with $\mathrm{MgO}$ expanding agent at different temperatures.

Fig. 4 shows the morphology of the hydrated product when cured at $20^{\circ} \mathrm{C}, 40^{\circ} \mathrm{C}$, and $80^{\circ} \mathrm{C}$ for the cement paste with $\mathrm{MgO}$ expansion agent. The expansion can be indirectly reflected by the compactness of the cement paste as shown in Fig. 4: increasing the temperature makes the $\mathrm{Mg}(\mathrm{OH})_{2}$ crystals join together to form a whole, making the structure denser, increasing the extrusion of the surrounding paste, and helping the expansion reaction [8].

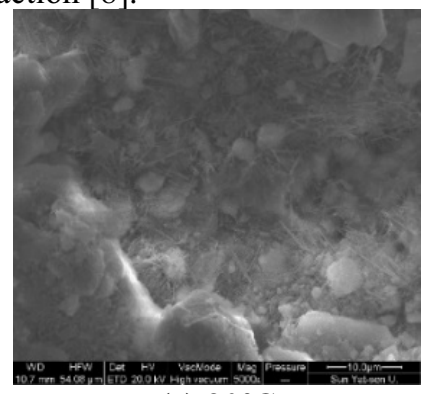

(a) $20^{\circ} \mathrm{C}$ 


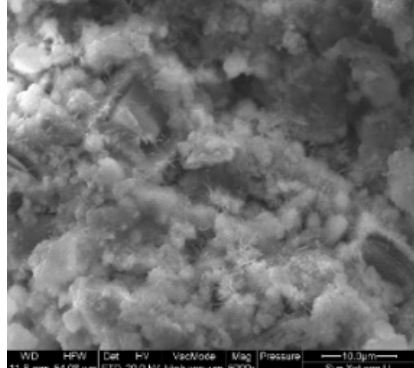

(b) $20^{\circ} \mathrm{C}$

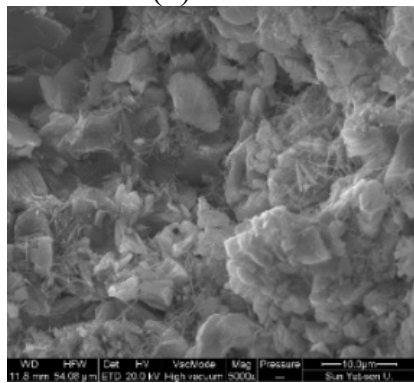

(c) $80^{\circ} \mathrm{C}$

Fig. 4. SEM images of cement paste mixed with $\mathrm{MgO}$ expansion agent (M-type) for curing 7 days in water.

Based on the above analysis, $\mathrm{MgO}$ expansion agent is not sensitive to the temperature range of $20 \sim 40^{\circ} \mathrm{C}$, but very sensitive to the temperature range of $40 \sim 80^{\circ} \mathrm{C}$. Therefore, the hydration and expansion rate of lightburned magnesia with medium and low activity depends on the reaction temperature and has strong temperature sensitivity [5]. The difference in the expansion efficiency and hydration reaction kinetic parameters of the $\mathrm{MgO}$ expansion agent is the main reason for the difference in temperature sensitivity.

\section{Conclusions}

(1) As the temperature increases, the expansion efficiency of the $\mathrm{MgO}$ expansion agent gradually increases.

(2) when the relative humidity is low $(\mathrm{RH} \leq 60 \%)$, the cement-based materials mixed with $\mathrm{MgO}$ expansion agents show shrinkage.

(3) $\mathrm{MgO}$ expansion agent is very sensitive to high temperature curing and low humidity curing.

\section{Acknowledgments}

The authors gratefully acknowledge the financial support provided by the Guangdong Province Key Field R\&D Program Project, No. 2019B111106002.

\section{References}

1. Guo J, Zhang S, Guo T, et al. (2020) Effects of UEA and $\mathrm{MgO}$ expansive agents on fracture properties of concrete.Construction and Building Materials., 263: 120245.

2. Cao F, Yan P. (2019) The influence of the hydration procedure of $\mathrm{MgO}$ expansive agent on the expansive behavior of shrinkage-compensating mortar. Constr uction and Building Materials., 202: 162-8.

3. Temiz H, Kantarc1 F, Emin İnceer M. (2015) Influence of blast-furnace slag on behaviour of dolomite used as a raw material of MgO-type expansive agent. Construction and Building Materials., 94: 528-35.

4. Chen X, Yang H-q, Li W-w. (2016) Factors analysis on autogenous volume deformation of $\mathrm{MgO}$ concrete and early thermal cracking evaluation. Construction and Building Materials., 118: 276-85.

5. Mo L, Fang J, Hou W, et al. (2019) Synergetic effects of curing temperature and hydration reactivity of $\mathrm{MgO}$ expansive agents on their hydration and expansion behaviours in cement pastes. Construction and Building Materials. 207: 206-17.

6. Thomas JJ, Musso S, Prestini I. (2014) Kinetics and Activation Energy of Magnesium Oxide Hydration. Journal of the American Ceramic Society., 97: 27582.

7. Li H, Tian Q, Zhao H, Lu A, et al. (2018) Temperature sensitivity of $\mathrm{MgO}$ expansive agent and its application in temperature crack mitigation in shiplock mass concrete. Construction and Building Materials., 170: 613-8.

8. Mo L, Deng M, Tang M. (2010) Effects of calcination condition on expansion property of MgO-type expansive agent used in cement-based materials. Cement and Concrete Research., 40: 43746. 